\title{
Subjective social isolation or loneliness in older adults residing in social housing in Ontario: a cross-sectional study
}

\author{
Gina Agarwal MBBS PhD, Melissa Pirrie MA, Angela Gao BHSc, Ricardo Angeles MD PhD, \\ Francine Marzanek BSc
}

\section{Abstract}

Background: Older adults face greater risk of social isolation, but the extent of social isolation among low-income older adults living in social housing is unknown. This study aims to explore the rate of, and risk factors contributing to, subjective social isolation or loneliness among older adults in social housing.

Methods: We conducted a cross-sectional study of data collected from a community program held in the common rooms of 55 social housing buildings in 14 communities across Ontario, Canada, from May 2018 to April 2019. Participants were program attendees aged 55 years and older who resided in the buildings. Program implementers assessed social isolation using the 3-Item Loneliness Scale from the University of California, Los Angeles and risk factors using common primary care screening tools. We extracted data for this study from the program database. We compared the rate of social isolation to Canadian Community Health Survey data using a 1 -sample $\chi^{2}$ test, and evaluated associations between risk factors and social isolation using univariate and multivariate logistic regressions.

Results: We included 806 residents in 30 buildings for older adults and 25 mixed-tenant buildings. Based on the 3-Item UCLA Loneliness Scale, 161 (20.0\%) of the 806 participants were socially isolated. For those aged 65 and older, the rate of social isolation was nearly twice that observed in the same age group of the general population $(36.1 \% \mathrm{v} .19 .6 \% ; p<0.001)$. Risk factors were age (65-84 yr v. 55-64 yr adjusted odds ratio [OR] 1.99, 95\% confidence interval [CI] 1.01-3.93), alcohol consumption (adjusted OR 2.45, 95\% Cl 1.09-5.54), anxiety or depression (adjusted OR 6.05, 95\% Cl 3.65-10.03) and income insecurity (adjusted OR $2.10,95 \% \mathrm{Cl} 1.24-3.53$ ). Protective factors were having at least 1 chronic cardiometabolic disease (adjusted OR 0.44 , $95 \% \mathrm{Cl} 0.24-0.80$ ), being physically active (adjusted $\mathrm{OR} 0.47,95 \% \mathrm{Cl} 0.30-0.73$ ) and having good to excellent general health (adjusted OR 0.60, 95\% Cl 0.39-0.90).

Interpretation: The high rate of social isolation in low-income older adults living in social housing compared with the general population is concerning. Structural barriers could prevent engagement in social activities or maintenance of social support, especially for older adults with income insecurity and anxiety or depression; interventions are needed to reduce subjective social isolation in this population.

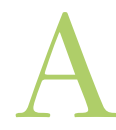

dults aged 65 and older are the fastest growing age group in Ontario, projected to increase from $16.9 \%$ of the population in 2018 to $23.4 \%$ by $2046 .{ }^{1}$ About 75000 older adults live in social housing in Ontario (i.e., subsidized, rent-geared-to-income units), with 50295 older adult households on wait lists for social housing in 2015, representing a third of households on such wait lists in Ontario. ${ }^{2}$ Social housing rental units are typically subsidized such that rent is $30 \%$ of household income, and eligibility is determined upon a complete financial assessment. Given the substantial and increasing number of older adults in Ontario living in social housing, it is relevant for stakeholders to understand factors influencing their health, such as social isolation.

Social isolation can be objectively defined as a lack of social contacts or limitation in the frequency of interaction with social network members, including family, friends and the larger community environment..$^{3-6}$ Loneliness is the subjective or psychological embodiment of social isolation $^{3-7}$ and will be the focus of the current study. In Canada, older adults are at high risk of subjective social isolation, ${ }^{7,8}$ with $19.6 \%$ of adults aged 65 and older reporting a lack of companionship, feeling left out or feeling isolated from others. $^{7,8}$ Older adults are particularly vulnerable given their

\section{Competing interests: None declared.}

This article has been peer reviewed.

Correspondence to: Gina Agarwal, gina.agarwal@gmail.com CMAJ Open 2021 September 28. DOI:10.9778/cmajo.20200205 
decreasing economic resources, reduced social networks, changes in household structure and limitations in function and mobility. 9

Subjective social isolation (i.e., loneliness) has been associated with living alone ${ }^{10}$ and poor health behaviours, such as smoking $^{3}$ and physical inactivity. ${ }^{11,12}$ It has also been associated with an increased risk of cardiovascular disease, stroke, depression, dementia and all-cause death., ${ }^{5,13-15}$ These health outcomes are particularly important for older adults living in social housing, given that this population reports poorer health and faces higher mortality rates than their unsubsidized counterparts. ${ }^{16,17}$ Subjective social isolation also affects the broader community by increasing the use of health and social services. ${ }^{18}$ For example, older adults with subjective social isolation have higher rates of certain high-cost and possibly avoidable health care services, such as hospital readmissions and long hospitalizations. ${ }^{19}$

Although low income has been associated with subjective social isolation in the general population, few studies have focused on social isolation in low-income older adults, ${ }^{20,21}$ and we could not identify any quantitative studies with older adults in social housing. We identified only 1 qualitative study of low-income older adults living in social housing, which found that they typically have less social support and therefore face an even greater risk of social isolation. ${ }^{22}$ By identifying risk factors in this population, targeted interventions and policies could be developed to prevent social isolation and thereby improve quality of life, ${ }^{17}$ reduce health inequalities ${ }^{19}$ and decrease health system costs associated with social isolation in an aging population. ${ }^{19}$ Given the gap in literature on this hard-to-reach population, we aimed to explore the rate of, and risk factors contributing to, social isolation in low-income older adults in social housing. We hypothesized that older adults living in social housing in Ontario would have higher rates of social isolation compared with the general population.

\section{Methods}

\section{Setting}

We conducted this cross-sectional study with data from the Community Paramedicine at Clinic (CP@clinic) program. CP@clinic is a voluntary, community-based program for health promotion and disease prevention that considers a holistic approach to health. It is held weekly in social housing for older adults. The program is advertised via posters throughout the building, encouraging residents to drop into sessions as a way to have a health check to prevent impending health issues. Paramedics hold sessions, conduct validated health-risk assessments through 1-on-1 clinical questioning, provide tailored health education and offer referrals to community resources on the basis of the results. The paramedics and CP@clinic program staff fax assessment results to the participant's family physician, with consent. The program is offered in social housing buildings for a 6-to-12-month period at a time. We have previously published a detailed description of CP@ clinic. $^{23}$

\section{Participants}

In accordance with the definition of "senior" used to determine housing eligibility by many Ontario Housing providers, we defined older adults as those aged 55 years and older. ${ }^{23}$ Study participants were older adults living in 55 designated social housing buildings for older adults or mixed tenants receiving the $\mathrm{CP} @$ clinic program. Buildings were in 14 regions across Ontario, Canada (i.e., Frontenac County, Grey County, Guelph, Halton Region, Hamilton, Hastings Region, Hearst, Iroquois Falls, Matheson, Norfolk Region, Peel Region, Sudbury, Timmins and York Region). Participants must have attended the program. The buildings designated for older adults had only tenants determined to be older adults according to the local housing authority's criteria; mixed-tenant buildings had residents of other ages as well.

\section{Data collection and measures}

We collected data between May 2018 and April 2019. After receiving participant consent, paramedics collected their data as part of the health-risk assessment screening during the course of an individual CP@clinic session; validated tools were used to reduce response bias., ${ }^{44-26}$ Paramedics entered data into the CP@clinic database, which is an electronic medical record (EMR). Paramedics are trained to use the assessments; additionally, day-to-day paramedic work now encompasses community paramedicine, which includes wellness check clinics (see Appendix 1, available at www.cmajopen.ca/ content/9/3/E915/suppl/DC1, for the subset of fields from the EMR included in this study).

We measured subjective social isolation using the validated University of California, Los Angeles (UCLA) 3-Item Loneliness Scale. This scale was already embedded within the EMR to measure subjective social isolation as it is a recommended primary care screening tool ${ }^{27}$ and has also been used by Statistics Canada. ${ }^{7}$ It assesses the participant's own perception of their loneliness, which differs from objective measures of social contacts. ${ }^{4}$ Participants answered the following 3 questions: "How often do you feel that you lack companionship?", "How often do you feel left out?" and "How often do you feel isolated from others?". The response options were "hardly ever," "some of the time" or "often," which corresponded to a score of 1,2 or 3 , respectively. The final score was the sum of all items, for a minimum score of 3 and maximum of 9 . We considered a participant with a score 6 or over as socially isolated in accordance with the guidance of the Centre for Addiction and Mental Health. ${ }^{27,28}$ The 2008-2009 Canadian Community Health Survey (CCHS) Healthy Aging Module also used this set of questions, ${ }^{7}$ which allowed us to compare our sample and the general population for people aged 65 and older. For the purpose of this comparison only, we used a score of 5 and over to define subjective social isolation, matching the cut-off used by the CCHS. ${ }^{7}$

We extracted risk factors from the CP@clinic EMR. Sociodemographic data included age, gender, ethnicity, marital status and living alone. Physical measures included weight, height and body mass index (BMI). In addition, participants self-reported their chronic cardiometabolic 
disease history (i.e., transient ischemic attack or stroke, heart attack, hypertension, hyperlipidemia and diabetes). We collected information on physical activity, ${ }^{11,12,24}$ alcohol use (any alcohol consumption v. nondrinker), ${ }^{29,30}$ current smoking status (current smoker v. former or never), ${ }^{3,31}$ income security ${ }^{11,25}$ and self-reported general health, ${ }^{11,26}$ based on literature associating these factors with social isolation. We measured health-related quality of life using 5 domains from the EQ-5D-3L tool, namely mobility, self-care, usual activities, pain or discomfort, and anxiety or depression. ${ }^{32,33}$

\section{Statistical analysis}

We performed descriptive statistics. For participants aged 65 and older, we used a 1 -sample $\chi^{2}$ test to compare subjective social isolation in the study sample to the fixed value reported by the 2008-2009 CCHS for the same age category.

For the full study sample (aged 55 and older), we used univariate binary logistic regression models to analyze associations for each independent variable (i.e., sociodemographic factors and health-related indicators) with social isolation. We used multivariable logistic regression models to evaluate the association of all independent variables with social isolation concurrently for participants with complete cases. We also replicated all regression models for the "lives alone" and "does not live alone" subgroups. To limit the number of variables in the regression models and to account for response options with small numbers, we collapsed some variables into fewer response categories (e.g., ethnicity, BMI categories, alcohol consumption, smoking status, presence of at least 1 chronic cardiometabolic disease). Some variables were also not included in the final model because of their very high correlation with another independent variable (e.g., marital status and living alone). We conducted model diagnostics to evaluate collinearity.

We verified data to complete the cases with missing gender at intake. We completed all analyses with IBM SPSS Statistics 17.0.

\section{Ethics approval}

This study was approved by the Hamilton Integrated Research Ethics Board (no. 14-645).

\section{Results}

The study included all 806 residents who attended the CP@clinic program in 30 buildings for older adults (3573 apartment units) and 25 mixed-tenant buildings (1770 apartment or townhouse units) (Figure 1). The 806 participants were most commonly female $(n=609$, $75.6 \%)$, aged $65-84$ years $(n=517,64.1 \%)$, white $(n=603$, $74.8 \%)$ and widowed $(n=310,38.5 \%)$. Most lived alone $(n=625,77.5 \%)$, had some high school education or less $(n=357,44.3 \%)$ and had a family doctor $(n=722,89.6 \%)$.

One in $5(20.0 \%)$ participants were classified as having social isolation (Table 1). Similarly, for participants aged 65 and older, $20.7 \%$ were classified as having social isolation. Complete data were available for 740 participants (91.8\%).

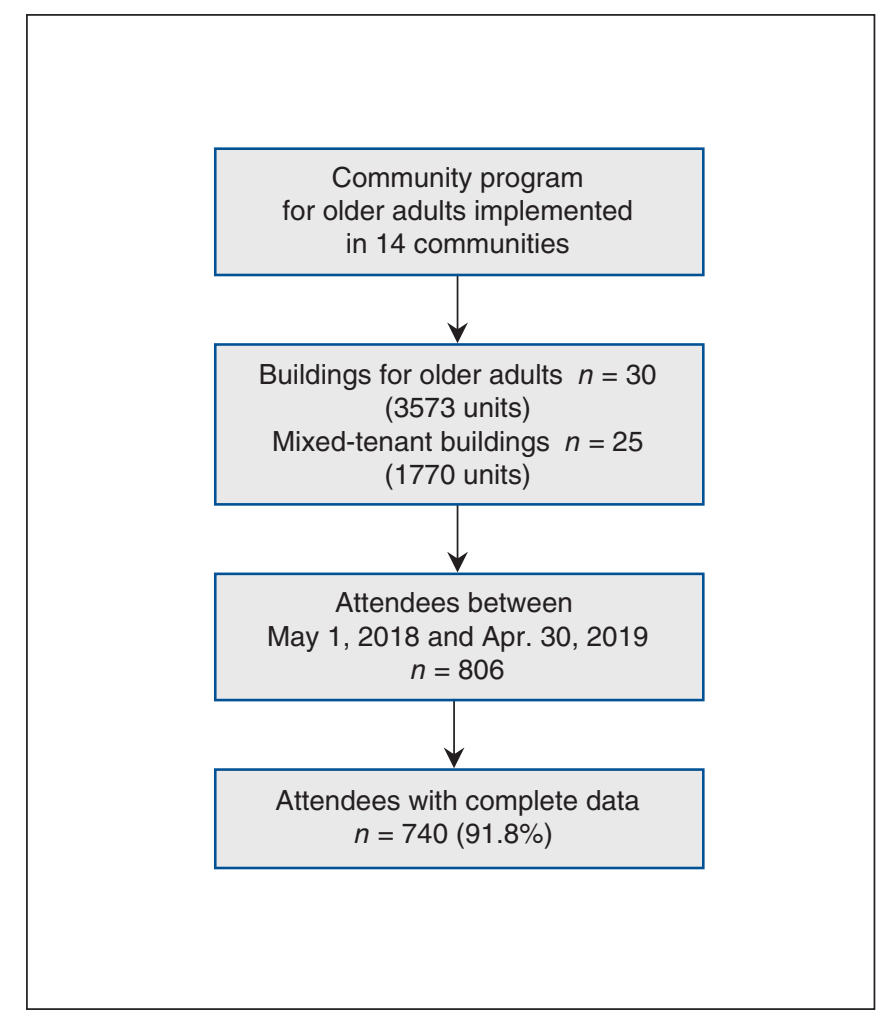

Figure 1: Participant flow diagram.

Among the 161 participants classified as having social isolation, a high proportion were current smokers $(n=40,24.8 \%)$, were income insecure $(n=47,29.2 \%)$ and had anxiety or depression $(n=114,70.8 \%)$, as well as having poor to fair health $(n=74,46.0 \%)$, a history of stroke or transient ischemic attack $(n=32,19.9 \%)$, and diabetes $(n=63,39.1 \%)$.

We compared the study sample to the general population in the 2008/09 CCHS Healthy Aging survey by matching the CCHS cut-off score of 5 on the UCLA 3-item Loneliness Scale and restricting the study sample to only those aged 65 and older. The rate of social isolation or loneliness among low-income older adults living in social housing was significantly higher than in the general population $(36.1 \%$ v. $19.6 \%$, $\chi^{2}=72.8, \mathrm{df}=1, p<0.001$ ).

The univariate regressions found significant factors associated with increased odds of social isolation, including living alone, low physical activity, alcohol consumption, smoking, poor to fair general health, mobility problems, self-care problems, problems doing usual activities, pain or discomfort, anxiety or depression and income insecurity (Table 2). When all factors were analyzed together in a multivariable regression, we did not identify any issues with multicollinearity (variance inflation factors 1.03-1.64). Significant risk factors for social isolation in the multivariable model were age (65-84 yr v. $55-64 \mathrm{yr}$ adjusted odds ratio [OR] 1.00, 95\% confidence interval [CI] 1.01-3.93), alcohol consumption (adjusted OR 2.45, 95\% CI 1.09-5.54), anxiety or depression (adjusted OR $6.05,95 \%$ CI 3.65-10.03) and income insecurity (adjusted OR 2.10, 95\% CI 1.24-3.53). Protective factors were having at least 1 chronic cardiometabolic disease 


\begin{tabular}{|c|c|c|c|}
\hline \multirow[b]{2}{*}{ Variable } & \multicolumn{3}{|c|}{ No. (\%) of participants } \\
\hline & $\begin{array}{l}\text { All participants } \\
\quad n=806\end{array}$ & $\begin{array}{c}\text { Not socially isolated } \\
n=645\end{array}$ & $\begin{array}{c}\text { Socially isolated } \dagger \\
\quad n=161\end{array}$ \\
\hline \multicolumn{4}{|l|}{ Demographics } \\
\hline \multicolumn{4}{|l|}{ Gender } \\
\hline Male & $197(24.4)$ & $154(23.9)$ & $43(26.7)$ \\
\hline Female & $609(75.6)$ & $491(76.1)$ & $118(73.3)$ \\
\hline \multicolumn{4}{|l|}{ Age, yr } \\
\hline $55-64$ & $124(15.4)$ & $107(16.6)$ & $17(10.6)$ \\
\hline $65-84$ & $517(64.1)$ & $407(63.1)$ & $110(68.3)$ \\
\hline$\geq 85$ & $153(19.0)$ & $124(19.2)$ & $29(18.0)$ \\
\hline No response & $12(1.5)$ & $7(1.1)$ & $5(3.1)$ \\
\hline \multicolumn{4}{|l|}{ Ethnicity } \\
\hline White & $603(74.8)$ & $480(74.4)$ & $123(76.4)$ \\
\hline Other & $203(25.2)$ & $165(25.6)$ & $38(23.6)$ \\
\hline \multicolumn{4}{|l|}{ Education } \\
\hline Some high school or less & $357(44.3)$ & $293(45.4)$ & $64(39.8)$ \\
\hline High school diploma & $185(23.0)$ & $151(23.4)$ & $34(21.1)$ \\
\hline Any postsecondary education & $250(31.0)$ & $192(29.8)$ & $58(36.0)$ \\
\hline No response & $14(1.7)$ & $9(1.4)$ & $5(3.1)$ \\
\hline \multicolumn{4}{|l|}{ Marital status } \\
\hline Divorced & $154(19.1)$ & $111(17.2)$ & $43(26.7)$ \\
\hline Common-law & $12(1.5)$ & $5(0.8)$ & $7(4.3)$ \\
\hline Married & 155 (19.2) & $140(21.7)$ & $15(9.3)$ \\
\hline Separated & $40(5.0)$ & $27(4.2)$ & $13(8.1)$ \\
\hline Single, never married & $95(11.8)$ & $68(10.5)$ & $27(16.8)$ \\
\hline Widowed & $310(38.5)$ & $259(40.2)$ & $51(31.7)$ \\
\hline No response & $40(5.0)$ & $35(5.4)$ & $5(3.1)$ \\
\hline Lives alone & $625(77.5)$ & 489 (75.8) & $136(84.5)$ \\
\hline No response & $6(0.7)$ & $5(0.8)$ & $1(0.6)$ \\
\hline \multicolumn{4}{|l|}{ Ontario region $\ddagger$} \\
\hline South West & 292 (36.2) & $223(34.6)$ & $69(42.9)$ \\
\hline Central West & $272(33.7)$ & 229 (35.5) & $43(26.7)$ \\
\hline South East & $125(15.5)$ & $97(15.0)$ & $28(17.4)$ \\
\hline North East & $117(14.5)$ & $96(14.9)$ & $21(13.0)$ \\
\hline Income insecure & $120(14.9)$ & 73 (11.3) & $47(29.2)$ \\
\hline No response & $2(0.2)$ & $1(0.2)$ & $1(0.6)$ \\
\hline Has a family doctor & $722(89.6)$ & $573(88.8)$ & $149(92.5)$ \\
\hline
\end{tabular}

(adjusted OR 0.44, 95\% CI 0.24-0.80), being physically active (adjusted OR 0.47 , 95\% CI 0.30-0.73) and having good to excellent general health (adjusted OR 0.60, 95\% CI 0.39-0.94).

Of the 625 participants who lived alone, $136(21.8 \%)$ reported social isolation. Univariate regressions found significant factors associated with increased odds of social isolation for this subgroup, including being female, age (65-84 $\mathrm{yr}$ v. 55-64 yr), low physical activity, alcohol consumption, smoking, having poor to fair general health, mobility problems, self-care problems, problems doing usual activities, anxiety or depression and income insecurity (Table 3). For the multivariable regression, we did not identify any multicollinearity (variance inflation factors 1.03-1.65). The multivariable regression found increased odds of social isolation 
Table 1 (part 2 of 2): Sociodemographic factors, health behaviours and health-related quality of life for all study participants and by social isolation subgroup

\begin{tabular}{|c|c|c|c|}
\hline \multirow[b]{2}{*}{ Variable } & \multicolumn{3}{|c|}{ No. (\%) of participants } \\
\hline & $\begin{array}{l}\text { All participants } \\
\quad n=806\end{array}$ & $\begin{array}{c}\text { Not socially isolated* } \\
\qquad n=645\end{array}$ & $\begin{array}{c}\text { Socially isolated } \dagger \\
\quad n=161\end{array}$ \\
\hline \multicolumn{4}{|l|}{ Chronic cardiometabolic disease } \\
\hline Had a stroke or TIA & $134(16.6)$ & $102(15.8)$ & $32(19.9)$ \\
\hline No response & $4(0.5)$ & $4(0.6)$ & $0(0.0)$ \\
\hline Had a heart attack & $101(12.5)$ & $78(12.1)$ & $23(14.3)$ \\
\hline No response & $3(0.4)$ & $2(0.3)$ & $1(0.6)$ \\
\hline History of hypertension & $558(69.2)$ & 457 (70.9) & $101(62.7)$ \\
\hline No response & $8(1.0)$ & $6(0.9)$ & $2(1.2)$ \\
\hline History of hyperlipidemia & $452(56.1)$ & 369 (57.2) & $83(51.6)$ \\
\hline No response & $4(0.5)$ & $2(0.3)$ & $2(1.2)$ \\
\hline Has diabetes & $251(31.1)$ & $188(29.1)$ & $63(39.1)$ \\
\hline No response & $4(0.5)$ & $3(0.5)$ & $1(0.6)$ \\
\hline \multicolumn{4}{|l|}{ Health behaviours } \\
\hline Low physical activity & $322(40.0)$ & $234(36.3)$ & $88(54.7)$ \\
\hline No response & $7(0.9)$ & $6(0.9)$ & $1(0.6)$ \\
\hline Alcohol drinker & $43(5.3)$ & $29(4.5)$ & $14(8.7)$ \\
\hline No response & $8(1.0)$ & $7(1.1)$ & $1(0.6)$ \\
\hline Current smoker & $117(14.5)$ & 77 (11.9) & $40(24.8)$ \\
\hline No response & $8(1.0)$ & $6(0.9)$ & $2(1.2)$ \\
\hline High BMI (overweight or obese) & $525(65.1)$ & 425 (65.9) & $100(62.1)$ \\
\hline No response & $64(7.9)$ & $50(7.8)$ & $14(8.7)$ \\
\hline \multicolumn{4}{|l|}{ Health status and quality of life } \\
\hline Self-reported poor to fair health & $254(31.5)$ & $180(27.9)$ & $74(46.0)$ \\
\hline No response & $5(0.6)$ & $4(0.6)$ & $1(0.6)$ \\
\hline Mobility problems & $411(51.0)$ & 319 (49.5) & $92(57.1)$ \\
\hline No response & $7(0.9)$ & $3(0.5)$ & $4(2.5)$ \\
\hline Self-care problems & $151(18.7)$ & 105 (16.3) & $46(28.6)$ \\
\hline No response & $9(1.1)$ & $4(0.6)$ & $5(3.1)$ \\
\hline Problems doing usual activities & $260(32.3)$ & $185(28.7)$ & $75(46.6)$ \\
\hline No response & $6(0.7)$ & $4(0.6)$ & $2(1.2)$ \\
\hline Pain or discomfort & $511(63.4)$ & $396(61.4)$ & $115(71.4)$ \\
\hline No response & $6(0.7)$ & $4(0.6)$ & $2(1.2)$ \\
\hline Anxiety or depression & $386(47.9)$ & 255 (39.5) & $114(70.8)$ \\
\hline No response & $18(2.2)$ & $13(2.0)$ & $5(3.1)$ \\
\hline \multicolumn{4}{|l|}{ Social isolation } \\
\hline Isolated & $204(25.3)$ & $59(9.1)$ & $145(90.1)$ \\
\hline Left out & 227 (28.2) & 75 (11.7) & $152(94.4)$ \\
\hline Lacks companionship & 295 (36.6) & $142(22.0)$ & $153(95.1)$ \\
\hline \multicolumn{4}{|c|}{$\begin{array}{l}\text { Note: BMI = body mass index, TIA }=\text { transient ischemic attack. } \\
\text { *Subjective social isolation (loneliness) score less than } 6 . \\
\text { †Subjective social isolation (loneliness) score of } 6 \text { or greater. } \\
\text { fSouth West: Grey County, Guelph, Halton Region, Hamilton, Norfolk Region. Central West: Peel Region, York Region. South } \\
\text { East: Frontenac County, Hastings Region. North East: Hearst, Iroquois Falls, Matheson, Sudbury, Timmins. }\end{array}$} \\
\hline
\end{tabular}




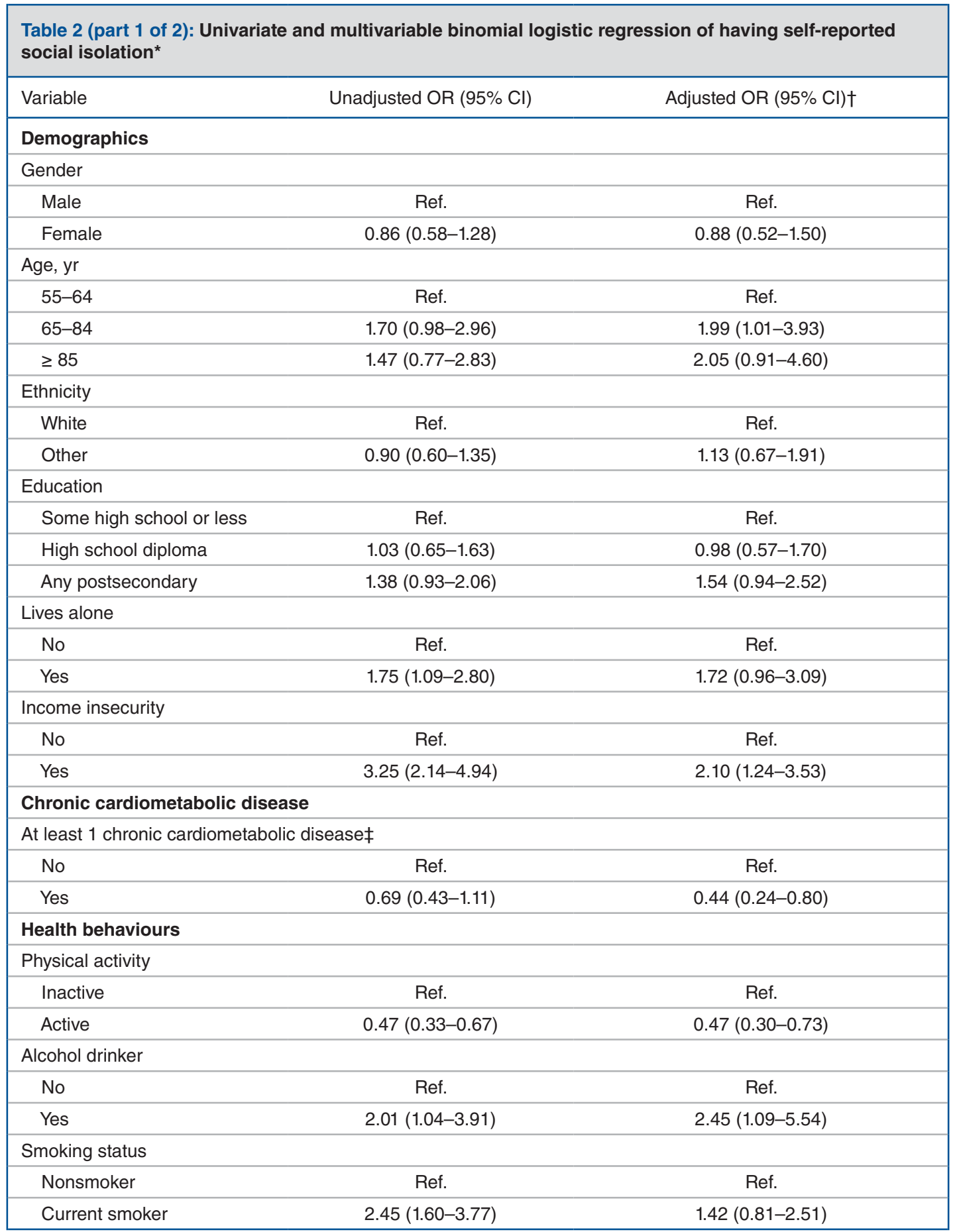

with alcohol consumption (adjusted OR 3.11, 95\% CI 1.277.63), anxiety or depression (adjusted OR 6.27, 95\% CI 3.59-10.97) and income insecurity (adjusted OR 1.93, 95\% CI 1.11-3.37), and decreased odds of social isolation with physical activity (adjusted OR 0.45, 95\% CI 0.27-0.73).

Of the 175 participants who did not live alone, 24 (13.7\%) reported social isolation. For this subgroup, univariate regressions found significantly increased odds of social isolation $(p<0.05)$ associated with income insecurity (OR 4.67,
95\% CI 1.52-14.37), smoking (OR 10.21, 95\% CI 3.2731.89), problems doing usual activities (OR 2.43, 95\% CI 1.01-5.87), and anxiety or depression (OR 4.99, 95\% CI 1.77-14.07), and decreased odds of social isolation with having good to excellent general health (OR 0.37, 95\% CI $0.15-$ 0.91) (Table 4). As the number of individuals who did not live alone and were socially isolated was small, it did not support conducting a multivariable logistic regression analysis for this subgroup. 


\begin{tabular}{|c|c|c|}
\hline Variable & Unadjusted OR (95\% Cl) & Adjusted OR (95\% Cl)† \\
\hline \multicolumn{3}{|l|}{ Health status and quality of life } \\
\hline \multicolumn{3}{|l|}{ General health } \\
\hline Poor to fair & Ref. & Ref. \\
\hline Good, very good, excellent & $0.45(0.32-0.65)$ & $0.60(0.38-0.94)$ \\
\hline \multicolumn{3}{|l|}{ Mobility problems } \\
\hline No problems & Ref. & Ref. \\
\hline Any problems & $1.43(1.01-2.04)$ & $0.85(0.51-1.43)$ \\
\hline \multicolumn{3}{|l|}{ Self-care problems } \\
\hline No problems & Ref. & Ref. \\
\hline Any problems & $2.14(1.43-3.19)$ & $1.46(0.80-2.66)$ \\
\hline \multicolumn{3}{|l|}{ Problems doing usual activities } \\
\hline No problems & Ref. & Ref. \\
\hline Any problems & $2.20(1.54-3.14)$ & $1.20(0.69-2.11)$ \\
\hline \multicolumn{3}{|l|}{ Pain or discomfort } \\
\hline None & Ref. & Ref. \\
\hline Any problems & $1.62(1.10-2.37)$ & $1.17(0.73-1.90)$ \\
\hline \multicolumn{3}{|l|}{ Anxiety or depression } \\
\hline None & Ref. & Ref. \\
\hline Any problems & $7.75(4.91-12.23)$ & $6.05(3.65-10.03)$ \\
\hline \multicolumn{3}{|c|}{$\begin{array}{l}\text { Note: } \mathrm{Cl}=\text { confidence interval, } \mathrm{OR}=\text { odds ratio, Ref. = reference. } \\
\text { *Logistic regressions compare participants who reported being socially isolated (score of } \geq 6 \text { ) v. not socially isolated (score }<6 \text { ). } \\
\text { †Multivariable regression included participants with complete data (socially isolated } n=141 \text {, not socially isolated } n=599 \text { ). } \\
\text { †At least } 1 \text { of hypertension, hyperlipidemia, heart attack, diabetes, or stroke or transient ischemic attack. }\end{array}$} \\
\hline
\end{tabular}

\section{Interpretation}

Our results show that 1 in 5 low-income older adults living in social housing had subjective social isolation or loneliness. For adults aged 65 and older, the rate of social isolation observed in this sample was nearly twice that reported in the general population. ${ }^{7}$ When adjusting for all of the risk factors simultaneously, physical activity and having at least 1 chronic cardiometabolic disease were consistently protective against social isolation, and alcohol consumption, poor to fair general health, anxiety or depression and income insecurity were risk factors. Living alone was more common among those who were socially isolated than not socially isolated ( $84 \%$ v. $75 \%)$; however, the results of this study suggest that in a population where most people do live alone, other factors (e.g., income insecurity) may be more strongly associated with feeling socially isolated than living alone.

Within the study population, income insecurity was significantly associated with greater odds of being socially isolated. Low income can prevent individuals from engaging in social activities or limit their ability to develop and maintain social support. ${ }^{34}$ In previous studies, low-income participants identified inaccessibility of amenities and a lack of opportunities to connect with others through education and employment as key causes of social isolation. ${ }^{20}$ Lack of a vehicle or efficient public transportation often prevented lower-income individuals from accessing community activities. ${ }^{20}$ Similar structural factors likely contribute to the increased rate of social isolation in our study population. For example, the Ontario NonProfit Housing Association reports that social housing sites, with high-rise buildings and lack of proximity to amenities, are not well-suited for the needs of older adults. ${ }^{35}$ Thus, older tenants with mobility issues or limited transportation lack accessible opportunities for social participation, with some reporting that they felt confined to their units. ${ }^{35,36}$

As the negative relationship between social isolation and health is well known, ${ }^{9}$ we might expect those with poor to fair health or who were physically inactive to be at greater odds for experiencing social isolation. Social isolation is a risk factor for negative health consequences, ranging from depression to coronary heart disease. ${ }^{13}$ These conditions may then exacerbate social isolation, as individuals with health concerns may struggle to visit friends and family or to engage in community activities. Furthermore, socially isolated individuals have been found to be less likely to exercise or consistently consume fruits and vegetables, and more likely to smoke; these negative health behaviours may worsen experiences of isolation. ${ }^{3}$ It has been theorized that social relationships benefit health primarily through encouraging health-promoting behaviours, such as exercise and adherence to therapeutic regimes, or by 


\begin{tabular}{|c|c|c|}
\hline Variable & $\begin{array}{l}\text { Unadjusted OR } \\
\quad(95 \% \mathrm{Cl})\end{array}$ & $\begin{array}{c}\text { Adjusted OR } \dagger \\
(95 \% \mathrm{Cl})\end{array}$ \\
\hline \multicolumn{3}{|l|}{ Demographics } \\
\hline \multicolumn{3}{|l|}{ Gender } \\
\hline Male & Ref. & Ref. \\
\hline Female & $0.57(0.36-0.89)$ & $0.72(0.39-1.32)$ \\
\hline \multicolumn{3}{|l|}{ Age, yr } \\
\hline $55-64$ & Ref. & Ref. \\
\hline $65-84$ & $1.90(1.03-3.49)$ & $2.07(0.98-4.36)$ \\
\hline$\geq 85$ & $1.45(0.70-3.00)$ & $1.78(0.73-4.36)$ \\
\hline \multicolumn{3}{|l|}{ Ethnicity } \\
\hline White & Ref. & Ref. \\
\hline Other & $1.04(0.65-1.66)$ & $1.19(0.66-2.14)$ \\
\hline \multicolumn{3}{|l|}{ Education } \\
\hline Some high school or less & Ref. & Ref. \\
\hline High school diploma & $1.18(0.71-1.96)$ & $1.14(0.63-2.09)$ \\
\hline Any postsecondary & $1.53(0.99-2.37)$ & $1.59(0.93-2.72)$ \\
\hline \multicolumn{3}{|l|}{ Income insecurity } \\
\hline No & Ref. & \\
\hline Yes & $3.00(1.91-4.73)$ & $1.93(1.11-3.37)$ \\
\hline \multicolumn{3}{|c|}{ Chronic cardiometabolic disease } \\
\hline \multicolumn{3}{|c|}{ At least 1 chronic cardiometabolic disease $\ddagger$} \\
\hline No & Ref. & Ref. \\
\hline Yes & $0.70(0.41-1.21)$ & $0.53(0.27-1.04)$ \\
\hline \multicolumn{3}{|l|}{ Health behaviours } \\
\hline \multicolumn{3}{|l|}{ Physical activity } \\
\hline Inactive & Ref. & Ref. \\
\hline Active & $0.44(0.30-0.64)$ & $0.45(0.27-0.73)$ \\
\hline \multicolumn{3}{|l|}{ Alcohol drinker } \\
\hline No & Ref. & Ref. \\
\hline Yes & $2.22(1.09-4.53)$ & $3.11(1.27-7.63)$ \\
\hline \multicolumn{3}{|l|}{ Smoking status } \\
\hline Nonsmoker & Ref. & Ref. \\
\hline Current smoker & $1.85(1.15-2.96)$ & $1.10(0.60-2.01)$ \\
\hline
\end{tabular}

discouraging negative health behaviours, such as smoking. ${ }^{37}$ In addition, social ties may also connect people to social networks that facilitate access to resources supportive of health, such as medical referrals or job opportunities. ${ }^{38}$ This cycle of social isolation and health consequences may contribute to the high rate of social isolation in our study population, which has previously been reported to have poorer health outcomes and less social support. ${ }^{22}$

Finally, in keeping with our findings, living alone is associated with social isolation. ${ }^{10}$ Previous research has found that lack of social support is common among older adults who live alone, which in turn contributes to social isolation. ${ }^{39}$ Mental health problems are also more common in low-income populations, ${ }^{40}$ and almost half of the current study sample reported having anxiety or depression. This risk factor was found to have the strongest association with social isolation in the multivariable models; however, the direction of this relation cannot be determined from this cross-sectional study. It is plausible that this is a bidirectional relation, whereby social isolation can result in anxiety and depression, and having anxiety or depression could result in being socially isolated..$^{41}$ Further research is needed to understand this complex dynamic better.

The health outcomes of social isolation are particularly important to low-income older adults in social housing, given 


\begin{tabular}{|c|c|c|}
\hline Variable & $\begin{array}{l}\text { Unadjusted OR } \\
(95 \% \mathrm{Cl})\end{array}$ & $\begin{array}{c}\text { Adjusted OR } \dagger \\
(95 \% \mathrm{Cl})\end{array}$ \\
\hline \multicolumn{3}{|l|}{ Health status and quality of life } \\
\hline \multicolumn{3}{|l|}{ General health } \\
\hline Poor to fair & Ref. & Ref. \\
\hline Good, very good, excellent & $0.49(0.33-0.72)$ & $0.67(0.41-1.10)$ \\
\hline \multicolumn{3}{|l|}{ Mobility problems } \\
\hline No problems & Ref. & Ref. \\
\hline Any problems & $1.63(1.10-2.42)$ & $1.08(0.62-1.90)$ \\
\hline \multicolumn{3}{|l|}{ Self-care problems } \\
\hline No problems & Ref. & Ref. \\
\hline Any problems & $1.98(1.27-3.10)$ & $1.28(0.67-2.44)$ \\
\hline \multicolumn{3}{|l|}{ Problems doing usual activities } \\
\hline No problems & Ref. & Ref. \\
\hline Any problems & $2.09(1.41-3.09)$ & $1.25(0.67-2.30)$ \\
\hline \multicolumn{3}{|l|}{ Pain or discomfort } \\
\hline None & Ref. & Ref. \\
\hline Any problems & $1.46(0.96-2.20)$ & $1.14(0.68-1.93)$ \\
\hline \multicolumn{3}{|l|}{ Anxiety or depression } \\
\hline None & Ref. & Ref. \\
\hline Any problems & $8.40(5.04-13.98)$ & $6.27(3.59-10.97)$ \\
\hline \multicolumn{3}{|c|}{$\begin{array}{l}\text { Note: } \mathrm{Cl}=\text { confidence interval, } \mathrm{OR}=\text { odds ratio, Ref. = reference. } \\
\text { *Logistic regressions compare participants who reported being socially isolated (score of } \geq 6 \text { ) v. not socially isolated (score }<6 \text { ) among } \\
\text { those who live alone. } \\
\text { †Multivariable regression included participants with complete data (socially isolated } n=121 \text {, not socially isolated } n=457 \text { ). } \\
\text { †At least } 1 \text { of hypertension, hyperlipidemia, heart attack, diabetes, or stroke or transient ischemic attack. }\end{array}$} \\
\hline
\end{tabular}

their health inequalities. Our work suggests that low-income older adults in social housing are at heightened risk of social isolation and the negative consequences that follow. Certain subgroups, such as those reporting income insecurity, are particularly vulnerable. Targeted interventions have the potential to support these individuals. For example, social prescribing is an emerging approach for addressing loneliness and social isolation. ${ }^{18}$ It involves referring individuals to community support and social programming, such as befriending schemes or group lessons. ${ }^{42}$ This approach could be very successful for lower-income older adults in social housing, as previous literature suggests they value relationships with community program providers. ${ }^{43}$ In addition, addressing social isolation in this population represents an opportunity to reduce health inequalities and health care costs. Older adults who are socially isolated are 4-5 times more likely to be hospitalized than those who are not socially isolated. ${ }^{44}$ Thus, directing support to this group could curb rising health care spending associated with an aging population.

\section{Limitations}

The current study evaluated a sample of older adults in social housing. We acknowledge that our sample may be biased by the large number of women who participated in the program.
However, there are no data published on the target population in Ontario with which we can compare to assess representation. This is a substantial gap in the research literature. The cross-sectional nature of our study limits our ability to ascertain the direction of the relation between social isolation and associated factors. Also, the large number of comparisons with uncorrected $p$ values and the small sample sizes may have resulted in type I and type II errors, respectively.

Participants may have underreported their experiences of social isolation because of a bias toward social desirability. We acknowledge that it would be difficult to administer these social isolation questions in any other way, given poor education and health literacy, as well as the nature of the population. ${ }^{45}$ Residents of social housing may be more suspicious of unfamiliar people and hesitant to participate, ${ }^{41}$ but paramedics are viewed as trusted professionals and advocates by this population. ${ }^{43}$ Furthermore, participants may have previously met the paramedics who collected the data, potentially contributing to self-reporting bias.

Finally, the sampling method may have increased the risk of self-selection bias. Advertisements for CP@clinic were placed around the social housing buildings, and participants chose whether they attended the program. Consequently, individuals who elected to participate may have been healthier, 


\begin{tabular}{|c|c|}
\hline \multicolumn{2}{|c|}{$\begin{array}{l}\text { Table } 4 \text { (part } 1 \text { of } 2 \text { ): Univariate binomial logistic regression } \\
\text { of having self-reported social isolation in participants who } \\
\text { do not live alone* }\end{array}$} \\
\hline Variable & Unadjusted OR (95\% Cl) \\
\hline \multicolumn{2}{|l|}{ Demographics } \\
\hline \multicolumn{2}{|l|}{ Gender } \\
\hline Male & Ref. \\
\hline Female & $2.04(0.80-5.21)$ \\
\hline \multicolumn{2}{|l|}{ Age, yr } \\
\hline $55-64$ & Ref. \\
\hline $65-84$ & $1.63(0.35-7.66)$ \\
\hline$\geq 85$ & $2.46(0.45-13.39)$ \\
\hline \multicolumn{2}{|l|}{ Ethnicity } \\
\hline White & Ref. \\
\hline Other & $0.86(0.36-2.09)$ \\
\hline \multicolumn{2}{|l|}{ Education } \\
\hline Some high school or less & Ref. \\
\hline High school diploma & $0.92(0.30-2.84)$ \\
\hline Any postsecondary & $1.10(0.38-3.15)$ \\
\hline \multicolumn{2}{|l|}{ Income insecurity } \\
\hline No & Ref. \\
\hline Yes & $4.67(1.52-14.37)$ \\
\hline \multicolumn{2}{|c|}{ Chronic cardiometabolic disease } \\
\hline \multicolumn{2}{|c|}{ At least 1 chronic cardiometabolic disease $\dagger$} \\
\hline No & Ref. \\
\hline Yes & $0.51(0.18-1.43)$ \\
\hline \multicolumn{2}{|l|}{ Health behaviour } \\
\hline \multicolumn{2}{|l|}{ Physical activity } \\
\hline Inactive & Ref. \\
\hline Active & $0.59(0.29-1.65)$ \\
\hline \multicolumn{2}{|l|}{ Alcohol drinker } \\
\hline No & Ref. \\
\hline Yes & $0.89(0.11-7.61)$ \\
\hline \multicolumn{2}{|l|}{ Smoking status } \\
\hline Nonsmoker & Ref. \\
\hline Current smoker & $10.21(3.27-31.89)$ \\
\hline
\end{tabular}

less socially isolated and more mobile than the general population of low-income older adults living in social housing. Nonetheless, this study provides valuable insight into a marginalized population that has not been well studied.

\section{Conclusion}

Canada's aging population is expected to create a large number of low-income older adults living in social housing because of limited finances and increased debt when entering retirement. We found that this population has higher rates of social isolation than the general population, and is therefore at greater risk of associated negative health consequences. We found several factors associated with increased odds of being
Table 4 (part 2 of 2): Univariate binomial logistic regression of having self-reported social isolation in participants who do not live alone*

Variable Unadjusted OR (95\% Cl)

Health status and quality of life

General health

Poor to fair Ref.

Good, very good, excellent

$0.37(0.15-0.91)$

Mobility problems

No problems

Ref.

Any problems

$0.71(0.29-1.73)$

Self-care problems

No problems

Ref.

Any problems

$2.41(0.90-6.50)$

Problems doing usual activities

No problems Ref.

Any problems $2.43(1.01-5.87)$

Pain or discomfort

No problems Ref.

Any problems $\quad 3.03$ (0.99-9.32)

Anxiety or depression

None

Ref.

Any problems

$4.99(1.77-14.07)$

Note: $\mathrm{Cl}=$ confidence interval, $\mathrm{OR}=$ odd ratio, Ref. = reference

*Logistic regressions compare participants who reported being socially isolated (score of $\geq 6$ ) v. not socially isolated (score $<6$ ) among those who live alone. †At least 1 of hypertension, hyperlipidemia, heart attack, diabetes, or stroke or transient ischemic attack.

socially isolated in our study population, such as self-reported anxiety or depression and income insecurity. These findings should inform the development of interventions to support vulnerable subgroups.

Although this study's strength is in addressing a gap in the international evidence base by assessing a hard-to-reach population, further longitudinal research is needed on the causal links between social isolation and negative health outcomes in this group. This research, and subsequent programs targeting social isolation in low-income older adults in social housing, can help improve well-being, address health inequities and reduce health care costs associated with Canada's aging population.

\section{References}

1. Ontario population projections update, 2019-2046. Toronto: Queen's Printer for Ontario: 2020. Available: https://www.fin.gov.on.ca/en/economy/demographics/ projections/ (accessed 2021 Mar. 2).

2. 2015 Waiting Lists Survey: ONPHA's report on waiting lists statistics for Ontario. Toronto: Ontario Non-Profit Housing Association. Available: www. onpha.on.ca/Content/PolicyAndResearch/Waiting_Lists_2015/2015_Waiting Lists_Survey.aspx (accessed 2021 Mar. 2).

3. Kobayashi LC, Steptoe A. Social isolation, loneliness, and health behaviors at older ages: longitudinal cohort study. Ann Behav Med 2018;52:582-93.

4. Hughes ME, Waite LJ, Hawkley LC, et al. A short scale for measuring loneliness in large surveys: results from two population-based studies. Res Aging 2004;26:655-72. 
5. Holt-Lunstad J, Smith TB, Layton JB. Social relationships and mortality risk: a meta-analytic review. PLoS Med 2010;7:e1000316.

6. Steptoe A, Shankar A, Demakakos P, et al. Social isolation, loneliness, and all-cause mortality in older men and women. Proc Natl Acad Sci U S A 2013; 110:5797-801.

7. Gilmour H. Social participation and the health and well-being of Canadian seniors. Ottawa: Statistics Canada; modified 2015 July 17. Available: https://www150. statcan.gc.ca/n1/pub/82-003-x/2012004/article/11720-eng.htm (accessed 2021 Mar. 2).

8. Social isolation of seniors - Volume 1: Understanding the issue and finding solutions. Ottawa: Employment and Social Development Canada; modified 2021 May 20. Available: https://www.canada.ca/en/employment-social-development/ corporate/partners/seniors-forum/social-isolation-toolkit-vol1.html (accessed 2021 Mar. 1)

9. Courtin E, Knapp M. Social isolation, loneliness and health in old age: a scoping review. Health Soc Care Community 2017;25:799-812.

10. Iliffe $S$, Kharicha K, Harari D, et al. Health risk appraisal in older people 2: the implications for clinicians and commissioners of social isolation risk in older people. Br 7 Gen Pract 2007;57:277-82.

11. Schrempft S, Jackowska M, Hamer M, et al. Associations between social isolation, loneliness, and objective physical activity in older men and women. BMC Public Health 2019;19:74.

12. Hawkley LC, Thisted RA, Cacioppo JT. Loneliness predicts reduced physical activity: cross-sectional \& longitudinal analyses. Health Psychol 2009;28: 354-63.

13. Valtorta NK, Kanaan M, Gilbody S, et al. Loneliness and social isolation as risk factors for coronary heart disease and stroke: systematic review and meta-analysis of longitudinal observational studies. Heart 2016;102: 1009-16.

14. Heikkinen R-L, Kauppinen M. Depressive symptoms in late life: a 10-year follow-up. Arch Gerontol Geriatr 2004:38:239-50.

15. Sutin AR, Stephan Y, Luchetti M, et al. Loneliness and risk of dementia. 7 Gerontol B Psychol Sci Soc Sci 2020;75:1414-22.

16. Gibler KM. Aging subsidized housing residents: a growing problem in U.S. cities. 7 Real Estate Res 2003;25:395-420.

17. Huguet N, Kaplan MS, Feeny D. Socioeconomic status and health-related quality of life among elderly people: results from the Joint Canada/United States Survey of Health. Soc Sci Med 2008;66:803-10.

18. Stall NM, Savage RD, Rochon PA. Loneliness in older adults. CMAf 2019;191:E476.

19. Gerst-Emerson K, Jayawardhana J. Loneliness as a public health issue: the impact of loneliness on health care utilization among older adults. Am 7 Public Health 2015;105:1013-9.

20. Stewart MJ, Makwarimba E, Reutter LI, et al. Poverty, sense of belonging and experiences of social isolation. $\mathcal{F}$ Poverty 2009;13:173-95.

21. Menec VH, Newall NE, Mackenzie CS, et al. Examining individual and geographic factors associated with social isolation and loneliness using Canadian Longitudinal Study on Aging (CLSA) data. PLoS One 2019;14:e211143.

22. Agarwal G, Brydges M. Effects of a community health promotion program on social factors in a vulnerable older adult population residing in social housing. BMC Geriatr 2018;18:95.

23. Agarwal G, McDonough B, Angeles R, et al. Rationale and methods of a multicentre randomised controlled trial of the effectiveness of a Community Health Assessment Programme with Emergency Medical Services (CHAP-EMS) implemented on residents aged 55 years and older in subsidised seniors' housing buildings in Ontario, Canada. BMF Open 2015; 5:e008110.

24. Godin G, Shephard RJ. Godin Leisure-Time Exercise Questionnaire. Med Sci Sports Exerc 1997;29:S36-8.

25. Brcic V, Eberdt C, Kaczorowski J. Development of a tool to identify poverty in a family practice setting: a pilot study. Int 7 Family Med 2011;2011:812182.

26. Bowling A. Just one question: If one question works, why ask several? $\mathcal{F}$ Epidemiol Community Health 2005;59:342-5.

27. Measuring your impact of loneliness in later life. London (UK): Campaign to End Loneliness. Available: https://www.campaigntoendloneliness.org/wp-content/ uploads/Loneliness-Measurement-Guidance1.pdf (accessed 2021 Mar. 2).

28. Scales to measure loneliness. Project $\mathrm{ECHO}{ }^{\circledR}$ at the Centre for Addiction and Mental Health (CAMH). Available: https://camh.echoontario.ca/ COVID-Resources/scales-to-measure-loneliness/ (accessed 2021 Mar. 2).

29. Akerlind I, Hörnquist JO. Loneliness and alcohol abuse: a review of evidences of an interplay. Soc Sci Med 1992;34:405-14.

30. Anderson GO. Loneliness among older adults: a national survey of adults 45+. Washington (DC): AARP Research; 2010. Available: https://www.aarp. org/research/topics/life/info-2014/loneliness_2010.html (accessed 2021 Feb. 26).
31. Shankar A, McMunn A, Banks J, et al. Loneliness, social isolation, and behavioral and biological health indicators in older adults. Health Psychol 2011;30:377-85.

32. Feng YS, Kohlmann T, Janssen MF, et al. Psychometric properties of the EQ-5D-5L: a systematic review of the literature. Qual Life Res 2021;30:647-73.

33. EQ-5D-3L user guide. Rotterdam (The Netherlands): EuroQol Research Foundation; 2018. Available: https://euroqol.org/wp-content/uploads/ 2021/01/EQ-5D-3LUserguide-14-0421.pdf (accessed 2021 June 2).

34. Hawthorne G. Measuring social isolation in older adults: development and initial validation of the friendship scale. Soc Indic Res 2006;77:521-48.

35. Aging in place in social housing. Toronto: Ontario Non-Profit Housing Association; 2016. Available: https://www.ighhub.org/sites/default/files/FocusON \%2520Aging\%2520in \%2520place\%2520in\%2520social\%2520housing.pdf (accessed 2020 May 1).

36. Strengthening social housing communities: helping vulnerable tenants maintain successful tenancies. Toronto: Ontario Non-Profit Housing Association; 2015. Available: https://onpha.on.ca/Content/PolicyAndResearch/Other_Research/ Stengthening\%20social\%20housing\%20communities.aspx (accessed 2021 June 2).

37. House JS. Social isolation kills, but how and why? Psychosom Med 2001;63:273-4.

38. Berkman L, Glass T. Social integration, social networks, social support and health. In: Berkman L, Kawachi I, editors. Social Epidemiology. New York: Oxford University Press; 2000:158-62.

39. Yeh S-CJ, Lo SK. Living alone, social support, and feeling lonely among the elderly. Soc Behav Personal 2004;32:129-38.

40. Mawani FN, Gilmour H. Validation of self-rated mental health. Health Rep 2010;21:61-75.

41. Domènech-Abella J, Mundó J, Haro JM, et al. Anxiety, depression, lonelines and social network in the elderly: longitudinal associations from The Irish Longitudinal Study on Ageing (TILDA). 7 Affect Disord 2019;246:82-8.

42. Rx: Community - Social prescribing in Ontario. Toronto: Alliance for Healthier Communities. Available: https://www.allianceon.org/Social -Prescribing (accessed 2021 Mar. 2).

43. Brydges M, Denton M, Agarwal G. The CHAP-EMS health promotion program: a qualitative study on participants' views of the role of paramedics. BMC Health Serv Res 2016;16:435.

44. National Seniors Council report on the social isolation of seniors. Gatineau (QC): National Seniors Council; 2014. Available: https://www.canada.ca/ content/dam/nsc-cna/documents/pdf/policy-and-program-development/ publications-reports/2014/Report_on_the_Social_Isolation_of_Seniors.pdf (accessed 2021 June 2).

45. Agarwal G, Habing K, Pirrie M, et al. Assessing health literacy among older adults living in subsidized housing: a cross-sectional study. Can f Public Health 2018;109:401-9.

Affiliations: Departments of Family Medicine (Agarwal, Pirrie, Angeles, Marzanek), and Health Research Methods, Evidence, and Impact (Agarwal), and Faculty of Health Sciences (Gao), McMaster University, Hamilton, Ont.

Contributors: Gina Agarwal, Melissa Pirrie, Ricardo Angeles and Francine Marzanek conceived and designed the study, and collected data. Melissa Pirrie, Angela Gao and Ricardo Angeles conducted statistical analyses. Gina Agarwal and Angela Gao drafted the manuscript, and Melissa Pirrie and Gina Agarwal participated in critical revision of the article. All authors have reviewed and gave final approval of the version to be published, and agreed to be accountable for all aspects of the work.

Funding: This study was funded by a Canadian Institutes of Health Research grant (MOP-133563).

Content licence: This is an Open Access article distributed in accordance with the terms of the Creative Commons Attribution (CC BY-NC-ND 4.0) licence, which permits use, distribution and reproduction in any medium, provided that the original publication is properly cited, the use is noncommercial (i.e., research or educational use), and no modifications or adaptations are made. See: https://creativecommons.org/licenses/by-nc-nd/4.0/

Data sharing: Limited deidentified data can be shared by the lead author upon request.

Supplemental information: For reviewer comments and the original submission of this manuscript, please see www.cmajopen.ca/content/9/3/ E915/suppl/DC1. 